\title{
Synthesis and Optical Characterization of Samarium Doped Lanthanum Orthophosphate Nanowires
}

\author{
Le Van $\mathrm{Vu}^{* 1}$, Duong Thi Mai Huong*2, Vu Thi Hai Yen*2 and Nguyen Ngoc Long \\ Center for Materials Science, Faculty of Physics, VNU University of Science, 334 Nguyen Trai, Thanh Xuan, Hanoi, Vietnam
}

$\mathrm{LaPO}_{4}$ nanowires doped with $0,1,2,3,4$ and $5 \mathrm{~mol} \% \mathrm{Sm}^{3+}$ were prepared by co-precipitation technique. These nanowires were studied by X-ray diffraction (XRD), transmission electron microscopy (TEM), photoluminescence (PL), photoluminescence excitation (PLE) spectra and energy-dispersive X-ray spectra (EDS). The PL spectra exhibited 4 groups of emission peaks, which are assigned to the transitions from the excited state ${ }^{4} G_{5 / 2}$ to the ground states ${ }^{6} H_{\mathrm{J}}$ with $J=5 / 2 ; 7 / 2 ; 9 / 2$ and $11 / 2 \mathrm{of} \mathrm{Sm}^{3+}$ ions. The intensity of PL related to Sm ${ }^{3+}$ ion reached to a maximum when the Sm doping content was 2 mol\%. The PLE spectra show 8 peaks, which are attributed to the absorption transitions from the ${ }^{6} H_{5 / 2}$ ground state to the ${ }^{4} K_{15 / 2},{ }^{4} D_{3 / 2},{ }^{6} P_{7 / 2},{ }^{4} F_{7 / 2},{ }^{6} P_{5 / 2},{ }^{4} G_{9 / 2},{ }^{4} I_{13 / 2}$ and ${ }^{4} I_{11 / 2}$ excited states. [doi:10.2320/matertrans.MA201526]

(Received January 27, 2015; Accepted June 25, 2015; Published August 7, 2015)

Keywords: co-precipitation, samarium doped lanthanum orthophosphate, nanowires, photoluminescence

\section{Introduction}

In recent years, rare-earth phosphates have proved to be very useful host lattices for luminescence, and have found widespread applications in various kinds of display devices. For instance, lanthanum orthophosphate $\left(\mathrm{LaPO}_{4}\right)$ has been used in lasers, fluorescent lamps, displays and sensors. In particular, $\mathrm{LaPO}_{4}$ is known as a promising host material for lanthanide ions to fabricate phosphors. Doping with different rare earth ions $\left(\mathrm{Eu}^{3+}, \mathrm{Tb}^{3+}, \mathrm{Ce}^{3+}, \mathrm{Pr}^{3+}\right.$, etc. $)$ allows to synthesize the phosphors emitting in a broad range of colours. $^{1-7)}$ To the best of our knowledge, most of previous works have been focused on the $\mathrm{Eu}^{3+}-, \mathrm{Tb}^{3+}-, \mathrm{Ce}^{3+}$-doped $\mathrm{LaPO}_{4},{ }^{1-3,6)}$ only a few works were devoted to the doping $\mathrm{LaPO}_{4}$ with $\mathrm{Sm}^{3+}$ ions. ${ }^{7)}$ In Ref. 7) the $\mathrm{LaPO}_{4}: \mathrm{Eu}^{3+}, \mathrm{Sm}^{3+}$ nanorods were synthesized by hydrothermal method and possessed a pure monoclinic structure.

In this article, hexagonal $\mathrm{LaPO}_{4}$ nanowires doped with $\mathrm{Sm}^{3+}$ ions were prepared by co-precipitation technique. The structure, the PL and PLE properties of $\mathrm{LaPO}_{4}: \mathrm{Sm}^{3+}$ nanowires have been investigated in detail.

\section{Experimental Procedure}

Undoped and $\mathrm{Sm}^{3+}$-doped $\mathrm{LaPO}_{4}$ nanowires were prepared by co-precipitation method from lanthanum oxide $\mathrm{La}_{2} \mathrm{O}_{3}$, samarium oxide $\mathrm{Sm}_{2} \mathrm{O}_{3}$ and ammonium dihydrogen phosphate $\mathrm{NH}_{4} \mathrm{H}_{2} \mathrm{PO}_{4}$ as precursors. The lanthanum nitrate $\mathrm{La}\left(\mathrm{NO}_{3}\right)_{3}$ and samarium nitrate $\mathrm{Sm}\left(\mathrm{NO}_{3}\right)_{3}$ solution were obtained by dissolving $\mathrm{La}_{2} \mathrm{O}_{3}$ and $\mathrm{Sm}_{2} \mathrm{O}_{3}$, respectively, in nitric acid $\mathrm{HNO}_{3}(30 \%)$ solution under heating with agitation for $15 \mathrm{~min}$. To prepare $\mathrm{NH}_{4} \mathrm{H}_{2} \mathrm{PO}_{4}$ solution, $30 \mathrm{mg}$ of $\mathrm{NH}_{4} \mathrm{H}_{2} \mathrm{PO}_{4}$ was dissolved in $60 \mathrm{~mL}$ of double distilled water under constant stirring for $15 \mathrm{~min}$. In a typical synthesis, stoichiometric amounts of $\mathrm{La}\left(\mathrm{NO}_{3}\right)_{3}$ and $\mathrm{Sm}\left(\mathrm{NO}_{3}\right)_{3}$ aqueous solutions were mixed. The molar ratio of Sm : La was $0,1,2$, 3,4 and $5 \mathrm{~mol} \%$. Then appropriate amounts of $\mathrm{NH}_{4} \mathrm{H}_{2} \mathrm{PO}_{4}$ solution were added into the mixed nitrate solution under

${ }^{* 1}$ Corresponding author, E-mail: levanvu@hus.edu.vn

${ }^{* 2}$ Graduate Student, VNU University of Science stirring for $3 \mathrm{~h}$ at room temperature. The resulting precipitate was filtered off and washed many times in water and ethanol to remove chemicals possibly remaining in the final products. The last products were dried in air at $65^{\circ} \mathrm{C}$ for $6 \mathrm{~h}$, obtaining white fine powders.

The synthesized nanowires were studied by X-ray diffractometer SIEMENS D5005, Bruker with $\mathrm{CuK}_{\alpha 1}$ irradiation $(\lambda=1.54056 \AA)$, transmission electron microscope JEOL JEM 1010, spectrofluorometer Fluorolog FL 3-22 Jobin-Yvon-Spex and X-ray spectrometer OXFORD ISIS 300 attached to the JEOL-JSM5410 LV scanning electron microscope.

\section{Results and Discussion}

TEM images of the $2 \% \mathrm{Sm}^{3+}$-doped LaPO4 samples are illustrated in Fig. 1. It can be seen clearly that the $\mathrm{LaPO}_{4}$ samples are composed of nanowires which are $7-8 \mathrm{~nm}$ in diameter and about several hundred $\mathrm{nm}$ in length.

XRD analysis of the synthesized $\mathrm{LaPO}_{4}$ nanowires showed that the samples exhibited a pure hexagonal structure (Fig. 2). All the diffraction peaks were in good agreement with the standard data JCPDS 04-0635. The lattice parameters calculated from XRD patterns are $a=b=7.08 \AA, c=$ $6.52 \AA$.

Figure 3 shows EDS spectra of the $\mathrm{LaPO}_{4}$ nanowires undoped and doped with $5 \% \mathrm{Sm}^{3+}$. The undoped $\mathrm{LaPO}_{4}$ nanowires mainly consist of the following elements: lanthanum $(\mathrm{La})$, phosphorus $(\mathrm{P})$ and oxygen $(\mathrm{O})$. The $5 \%$ $\mathrm{Sm}^{3+}$-doped $\mathrm{LaPO}_{4}$ nanowires exhibit some peaks related to samarium (Sm) element, indicating the penetration of $\mathrm{Sm}^{3+}$ ions into the host lattice.

The room temperature PL spectra of $\mathrm{LaPO}_{4}$ nanowires undoped and doped with 1, 2, 3, 4 and $5 \% \mathrm{Sm}^{3+}$ excited by $402 \mathrm{~nm}$ wavelength are represented in Fig. 4. The undoped nanowires do not exhibit the groups of emission peaks in the wavelength range from 525 to $750 \mathrm{~nm}$. The $\mathrm{Sm}^{3+}$-doped $\mathrm{LaPO}_{4}$ nanowires show 4 groups of emission peaks at 560 , 596, 645 and $705 \mathrm{~nm}$. Figure 4 and its inset indicate that the intensity of PL spectra related to $\mathrm{Sm}^{3+}$ ion reaches to a maximum when the Sm doping content is $2 \mathrm{~mol} \%$, which is 


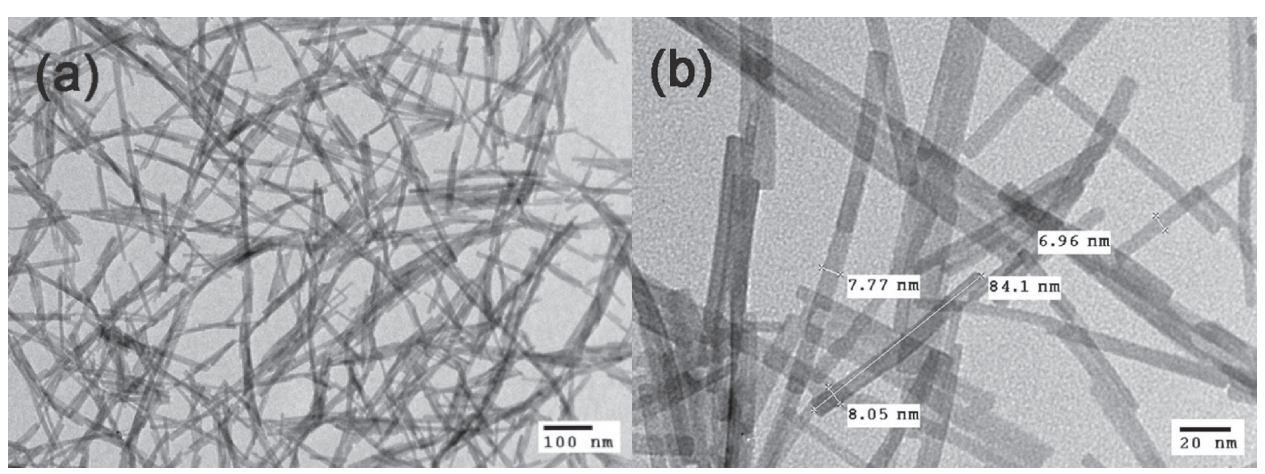

Fig. 1 (a) Low magnified and (b) high magnified TEM images of the $\mathrm{LaPO}_{4}$ doped with $2 \% \mathrm{Sm}^{3+}$.

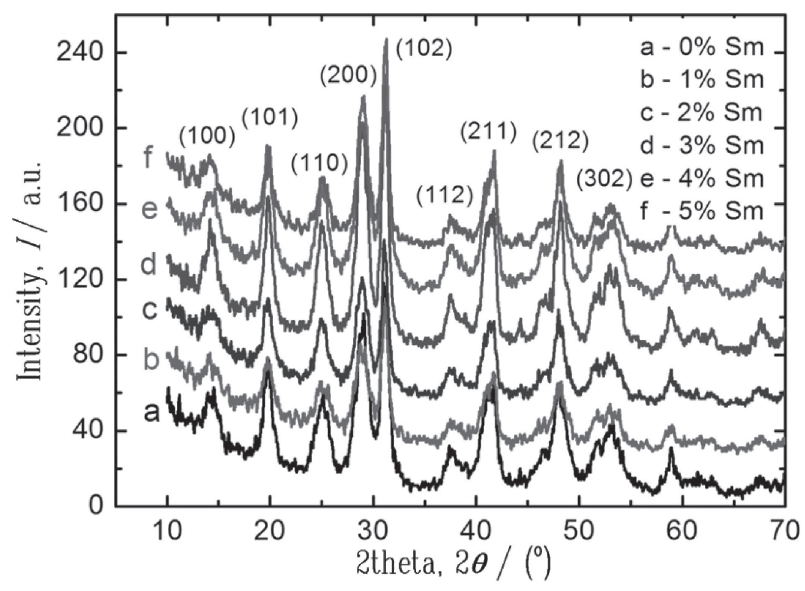

Fig. 2 XRD patterns of the $\mathrm{LaPO}_{4}$ nanowires doped with different $\mathrm{Sm}^{3+}$ contents.

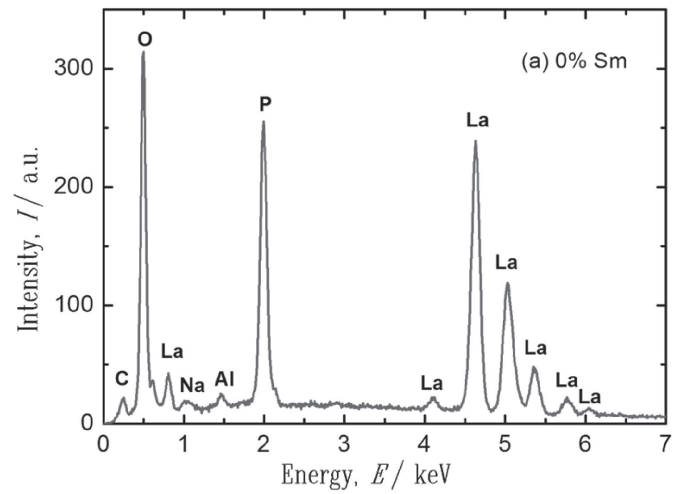

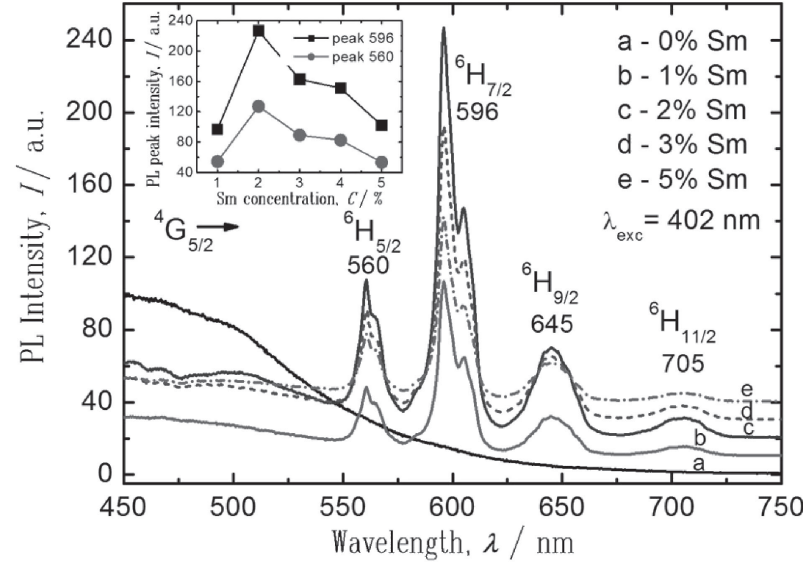

Fig. 4 PL spectra of $\mathrm{LaPO}_{4}$ nanowires doped with different $\mathrm{Sm}^{3+}$ contents. The inset shows the intensity of 596 and $560 \mathrm{~nm}$ peaks as a function of Sm concentration.

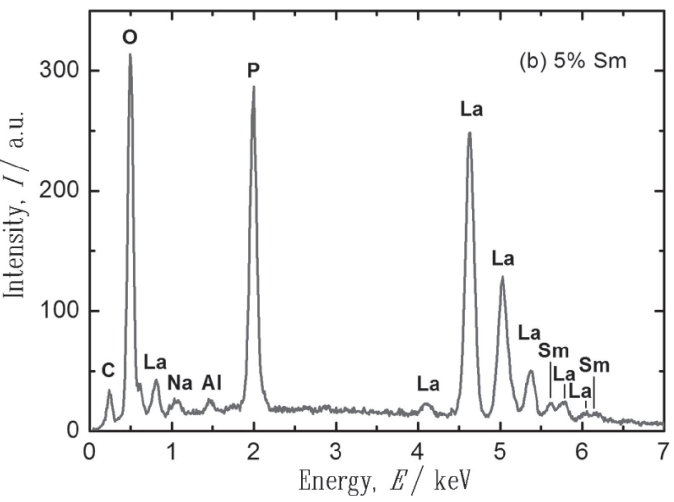

Fig. 3 EDS spectra of the $\mathrm{LaPO}_{4}$ nanowires (a) undoped and (b) doped with $5 \% \mathrm{Sm}^{3+}$.

in good agreement with Ref. 7). However, PL intensity decreases with further increasing the doping concentration. It is well known that, in general, when the concentration of an activator is higher than an appropriate value, the luminescence of the phosphor is usually lowered. This effect is called concentration quenching. The origin of this effect is known to be one of the following: ${ }^{8)}$

(1) Excitation energy is lost from the emitting state due to cross-relaxation between the activators.

(2) Excitation migration due to the resonance between the activators is increased with increasing the concentration, so that the energy reaches remote quenching centers or the surface states acting as quenching centers.
(3) The activator ions are paired or coagulated and are changed to a quenching center.

The decrease of luminescence intensity in our $\mathrm{Sm}^{3+}$-doped $\mathrm{LaPO}_{4}$ samples at the $\mathrm{Sm}^{3+}$ ion concentrations higher than $2 \mathrm{~mol} \%$ can be attributed to the concentration quenching effect due to the pairing or coagulation of the $\mathrm{Sm}^{3+}$ ions. The groups of peaks at 560, 596, 645 and $705 \mathrm{~nm}$ are assigned to the transitions from the excited state ${ }^{4} G_{5 / 2}$ to the ground states ${ }^{6} H_{\mathrm{J}}$ with $J=5 / 2 ; 7 / 2 ; 9 / 2$ and $11 / 2$ of $\mathrm{Sm}^{3+}$ ions, ${ }^{9)}$ respectively.

It is worth noting that all the emission line groups have the same excitation spectra. Typical PLE spectrum monitored at $596 \mathrm{~nm}$ emission line of $2 \% \mathrm{Sm}^{3+}$-doped $\mathrm{LaPO}_{4}$ nanowires 


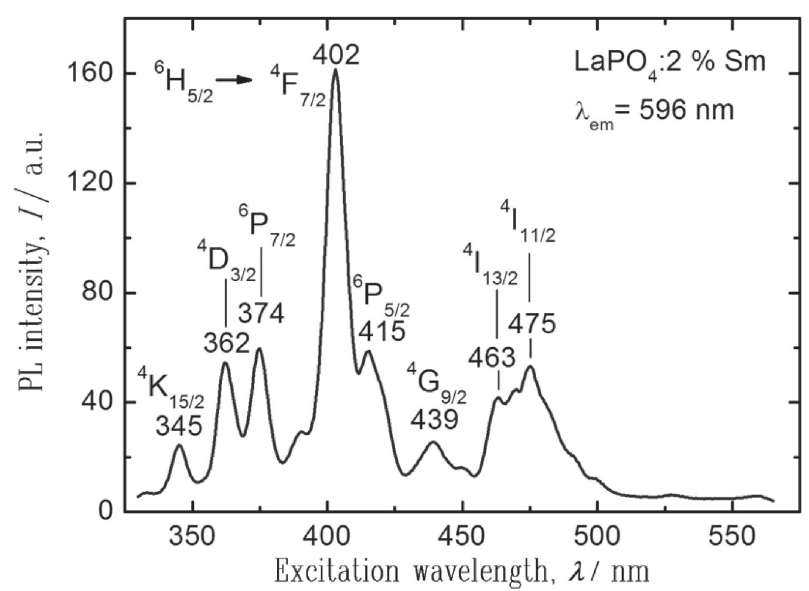

Fig. 5 PLE spectrum monitored at $596 \mathrm{~nm}$ emission line of $\mathrm{LaPO}_{4}$ nanowires doped with $2 \% \mathrm{Sm}^{3+}$.

is depicted in Fig. 5. The excitation lines located around $345,362,374,402,415,339,363$ and $475 \mathrm{~nm}$ are attributed to the absorption transitions from the ${ }^{6} \mathrm{H}_{5 / 2}$ ground state to the ${ }^{4} K_{15 / 2},{ }^{4} D_{3 / 2},{ }^{6} P_{7 / 2},{ }^{4} F_{7 / 2},{ }^{6} P_{5 / 2},{ }^{4} G_{9 / 2},{ }^{4} I_{13 / 2}$ and ${ }^{4} I_{11 / 2}$ excited states, ${ }^{9)}$ respectively.

\section{Conclusion}

The $\mathrm{Sm}^{3+}$-doped $\mathrm{LaPO}_{4}$ nanowires were prepared by coprecipitation technique. The XRD analysis showed that the nanowires exhibited a pure hexagonal structure. The intensity of PL spectra related to $\mathrm{Sm}^{3+}$ ions reached to a maximum when the Sm doping content was 2 mol\%. The PL and PLE spectra originate from the optical transitions between the ground and excited states within $\mathrm{Sm}^{3+}$ ions in the $\mathrm{LaPO}_{4}$ host lattice.

\section{Acknowledgments}

The authors would like to thank Vietnam National University for financially supporting this research through Project No QGTD 13 04. Authors thank the VNU Hanoi project "Nano Science and Nano Technology" for providing the equipments to complete this work.

\section{REFERENCES}

1) V. Pankratov, A. I. Popov, S. A. Chernov, A. Zharkouskaya and C. Feldmann: Phys. Status Solidi B 247 (2010) 2252-2257.

2) M. Yang, H. You, K. Liu, Y. Zheng, N. Guo and H. Zhang: Inorg. Chem. 49 (2010) 4996-5002.

3) R. Gao, D. Qian and W. Li: Trans. Nonferrous Met. Soc. China 20 (2010) 432-436.

4) A. M. Srivastava, A. A. Setlur, H. A. Comanzo, W. W. Beers, U. Happek and P. Schmidt: Opt. Mater. 33 (2011) 292-298.

5) L. Macalik, P. E. Tomaszewski, A. Matraszek, I. Szczygieł, P. Solarz, P. Godlewska, M. Sobczyk and J. Hanuza: J. Alloy. Compd. 509 (2011) 7458-7465.

6) D. T. M. Huong, L. T. Trang, L. V. Vu and N. N. Long: J. Alloy. Compd. 602 (2014) 306-311.

7) G. Li, L. Li, M. Li, Y. Song, H. Zou, L. Zou, X. Xu and S. Gan: Mater. Chem. Phys. 133 (2012) 263-268.

8) Phosphor Handbook, $2^{\text {nd }}$ ed., ed. by W. M. Yen, S. Shionoya, H. Yamamoto, (CRC Press Taylor \& Francis Group, 2007) p. 106.

9) C. K. Jayasankar and E. Rukmini: Opt. Mater. 8 (1997) 193-205. 